\title{
sciendo
}

\section{Effects of Slackline Training on Acceleration, Agility, Jump Performance and Postural Control in Youth Soccer Players}

\author{
by \\ Javier Fernández-Rio ${ }^{1}$, Luis Santos², Benjamín Fernández-García ${ }^{3}$, Roberto Robles ${ }^{4}$, \\ Iván Casquero ${ }^{5}$, Raúl Paredes ${ }^{5}$
}

\begin{abstract}
The goal of this study was to assess the effects of a supervised slackline training program in a group of soccer players. Thirty-four male division I under-19 players (16.64 \pm 0.81 years) agreed to participate in the study. They were randomly divided into an experimental group (EG) and a control group (CG). The first group (EG) followed a 6-week supervised slackline training program (3 sessions/week; 5-9 min/session), while the CG performed only regular soccer training. Several variables were assessed in all participants: acceleration (20-m sprint test), agility ( $90^{\circ}$ turns test), jump performance (squat jump, countermovement jump), and postural control (Center of Pressure (CoP) testing: length, area, speed, Xmean, Ymean, Xspeed, Yspeed, Xdeviation, Ydeviation). Ratings of perceived exertion and local muscle ratings of perceived exertions were also recorded after each slackline training session. At post-tests, there was a significant increase only in the EG in acceleration, agility, squat jump and countermovement jump performance, as well as several CoP variables: area in the bipedal support on a firm surface, and length, area and speed in the left leg on a firm surface. The program was rated as "somewhat hard" by the players, while quadriceps, gastrocnemius and tibialis anterior were the most exerted muscles while slacklining. In conclusion, slackline training can be an effective training tool for young, high-level soccer players.
\end{abstract}

Key words: soccer, performance, motor abilities, physical fitness.

\section{Introduction}

Soccer, with millions of licenses, is probably the world's most popular sport. Player's performance has been associated with technical, tactical, physical, physiological and mental factors (Stølen et al., 2005). Regarding physical/physiological elements, strength and power have been considered equally important as endurance (Mohr et al., 2003), and significant relationships have been observed between strength, acceleration and movement velocity (Wisløff et al., 2004). Furthermore, an increase in players' strength has been linked to improvements in significant soccer skills such as turning,

sprinting, jumping and changing pace, as well as to injury prevention (Stølen et al., 2005). Therefore, it has been suggested that strength development should be pursued on a weekly basis. On the other hand, acceleration seems to be another important element in soccer players' performance. Turner and Stewart (2014) reported that $96 \%$ of sprint bouts performed in a match were of shorter distances than 30 meters. Moreover, players change direction every 2-4 seconds (Verheijen, 1997), and acceleration plays an important part. Agility has been defined as the ability to maintain and control a correct body position while quickly

1 - Department of Educational Sciences; University of Oviedo; Oviedo; Spain.

2 - Department of Sport Sciences; University of León; León; Spain.

3 - Department of Functional Biology; University of Oviedo; Oviedo; Spain.

4 - R.C. Deportivo de la Coruña; Coruña, Spain.

5 - Department of Educational Sciences; University of Oviedo; Oviedo; Spain.

Authors submitted their contribution to the article to the editorial board.

Accepted for printing in the Journal of Human Kinetics vol. 67/2019 in June 2019. 
changing direction (Sporis et al., 2010) and its improvement has been connected with a positive impact on soccer performance (Little and Williams, 2005). Finally, adequate postural control systems (PCS) have also been considered crucial in soccer to prevent injuries and excel in competition (Biéc et al., 2015). Elite players have been found to develop the ability to rely less on vision and more on proprioception (Paillard and Noe, 2006). Therefore, strength, acceleration, agility and balance are considered important abilities to develop in soccer players.

Slacklining has become increasingly popular as a recreational activity. Individuals try to maintain balance on a polyester band placed between 2 anchor points, while performing different exercises (i.e., stand, walk, jump, turn, etc.). Slacklining allows very high movement variability as it provides only a small non-fixed base of support and produces very fast mediolateral perturbations to the body (Pfusterschmied et al., 2013a). Previous studies on the effects of slackline training in seniors, healthy adults and young children have produced contradictory results. Donath et al. (2016) found improvements in slackline standing performance, and reductions of lower limb and trunk muscle activity, but static balance, ankle strength and power were not affected. On the contrary, Thomas and Kalicinski (2016) concluded that slacklining had a positive impact on postural control and the reduction of fall risk in older adults. Pfusterschmied et al. (2013b) found that it could improve postural stability in a single leg stance on a stable surface. On the contrary, no positive effects were found on jumping performance (Donath et al., 2016).

Recent studies on supervised slackline training programs applied to athletes have yielded positive effects on postural control and jump performance in judokas (Santos et al., 2014) and female basketball players (Santos et al., 2016), and on sensorimotor control in young soccer players (Jäger et al., 2017). It has been hypothesized that when individuals try not to fall from the polyester band, balance demand increases and muscles are highly recruited to avoid falls. In both studies, the supervised slackline training programs were included in the athletes' regular warm-up routine as a cross-training tool. There seems to be a need to assess if these positive effects can be obtained in other sports and athletes.
The goal of the present study was to assess the effects of a supervised slackline training program in a group of young soccer players. The first hypothesis was that the program would produce positive effects on the players' acceleration, agility and jumping performance. The second hypothesis was that the program would have a positive effect on the participants' postural control. Finally, the third hypothesis was that slackline training would be rated as light by the players, and that the leg muscles would be stressed the most.

\section{Methods}

Participants

Thirty-four male youth high-level soccer players (16.64 \pm 0.81 years) enrolled in the same club agreed to participate in the study. They all competed in the under-19 Division-I national league. The study was approved by the University of Oviedo Ethics Committee. Informed written consent was obtained from all participants' parents. The inclusion criteria were: national-level, $>5$ years of training experience in soccer, and regular attendance to practice and matches $(>90 \%)$. Prior to study enrolment, participants underwent a physical examination by the club medical staff to validate their health status. Age, body height, body mass, and the sum of six skinfolds (abdominal, suprailiac, tricipital, subescapular, thigh, and medial leg) using a skinfold caliper (Holtain ${ }^{\circledR}, \mathrm{UK}$ ) were determined prior and at the end of the study (Table 1). None of the participants had any experience in slackline training. They were randomly distributed into an Experimental Group (EG, Slackline, $N=18$ ) and a Control Group (CG, no Slackline, $\mathrm{N}=16$ ). Unfortunately, five dropouts occurred due to injuries. Data on those players were not included in analysis.

Procedures

All players participated in the same weekly soccer training program, which included four sessions (90 min each). Additionally, the EG followed a 6-week supervised slackline program during three of the weekly sessions, lasting 5-9 minutes. It was designed as a cross-training tool and conducted prior to the regularly scheduled warm-ups. The program was fitted in the first half of the soccer season when players were well conditioned. Three Gibbon Slackline ${ }^{\mathrm{TM}}$ lines (ID Sports, Stuttgart, Germany; length: $25 \mathrm{~m}$, width: 
$5 \mathrm{~cm}$ ) were set $50 \mathrm{~cm}$ above the floor. Tasks, all performed barefoot, were selected based on previous studies (Keller et al., 2012; Pfusterschmied et al., 2013a, b; Santos et al., 2014, 2016). Three repetitions of each task were performed, with each one lasting $30 \mathrm{~s}$ and rest intervals of $10 \mathrm{~s}$ in-between (Table 2). One assistant stood next to the slackline with one arm held upright for the players to use it as a support when necessary.

Measures

At pre- and post-test, all participants performed the same assessment tests in the same order. They were conducted in separate days: centre of pressure $(\mathrm{CoP})$ and jump performance were evaluated on day 1 , while acceleration and agility on day 2 (three days later). A regular soccer warm-up was performed prior to each testing session.

Acceleration. Participants performed the 20-m Sprint Test on their practice field (Sporis et al., 2010). For timing, two pairs of electronic time sensors with dual beam timing gates (Photo-cell system by DigiTimes, Digitest, Oulu, Finland) were set at the starting and finish lines. The test was performed 3 times ( 3 trials), with a rest interval of 3 minutes in-between. The average time was included in the statistical analysis.

Agility. Participants performed the Sprint with $90^{\circ}$ Turns Test $\left(S 90^{\circ}\right)$ on their practice field (Sporis et al., 2010). The same device and the same protocol ( 3 trials, 3 min rest intervals) were used to assess acceleration. The average data were included in further analysis.

Jump performance. Participants performed two tests on a contact time platform (Ergojump ${ }^{\circledR}$, Finland): squat jump (SJ) and countermovement jump (CMJ) (Bosco et al., 1983). Three attempts were performed, with a rest interval of $1 \mathrm{~min}$. The average flight times were included in further analysis. The SJ test was always performed first.

CoP. CoP measurements were obtained through a footscan baropodometric platform (FreeMED $^{\mathrm{TM}}$ Sensormedica, S.A.S.; Rome, Italy). Data were registered and analysed using Free-Step software 1.0.3. It assesses the individuals' CoP position in two planes: sagittal (anterior-posterior perturbations) and transverse (medio-lateral perturbations). A sampling frequency of $100 \mathrm{~Hz}$ with a cut-off frequency of $10 \mathrm{~Hz}$ was used for data collection (Ruhe et al., 2010). Tests conducted were as follows: bipedal support, left leg support, and right leg support over firm and compliant surfaces with eyes open. The platform's firm surface was transformed into a complaint one using a flexible balance disc $(1 \mathrm{~kg}, 6 \mathrm{~cm})$. Stance width was set at 17 cm (Mouzat et al., 2004). Data acquisition duration was $10 \mathrm{~s}$ (McGuine et al., 2000). Positioning variables were assessed as they express PCS globally using length (CoP displacement), area (PCS precision area), and speed (postural reactions) data. Three attempts of each test were recorded (1 min rest interval), and the average value was included in further analysis.

RPE. Morgan and Borg (1976) showed that during long intervals of work the rate of perceived exertion (RPE) change was a sensitive indicator of exhaustion. The 6-20 Borg scale was explained prior to the beginning of the program, and participants were asked to rate their perceived exertion at the end of each session.

LRPE. Nilsson et al. (2002) validated a modified version of Borg's scale to estimate the perceived exertion in specific body parts (muscles). At the end of each training session, participants were given an anatomical diagram showing anterior and posterior views of the body, and they were asked to identify the muscle groups they felt had been exerted.

Statistical Analysis

All data were analysed using the SPSS 22.0 version (IBM, Chicago, IL). A one-way analysis of variance (ANOVA), selecting the Levene's test ( $p>$ $0.05)$, was used to assess initial homogeneity between the two study groups at pre-test (Martin and Bridgmon, 2012). Reliability of all dependent variables (acceleration, agility, $\mathrm{CoP}$ and jump performance) was calculated at pre- and post-tests using an Intraclass Correlation Coefficient (ICC) model. Data used to calculate the ICC were obtained from a 2-way fixed-effects analysis of variance (ANOVA), using the ICC 3,1 model (ICC 3,1 $=$ MSs-MSE/MSs+(k-1)MSE) (Weir, 2005). Reliability values were defined as poor $\leq 0.00$, slight $=0.00-0.20$, fair $=0.21-0.40$, moderate $=0.41-0.60$, substantial $=$ $0.61-0.80$, and almost perfect $=0.81-1.00$ (Beckerman et al., 2001). Pre- and post-tests descriptive statistics were also calculated. Covariance analyses with the post-test scores (post-test MANCOVA and ANCOVA) with the pre-test as covariate were conducted, which allowed verification of the impact of the program. Finally, effect size (Cohen's d) was also assessed 
(small < 0.5; moderate 0.50-0.79; large $\geq 0.80$ ).

\section{Results}

Demographic characteristics did not differ between the EG and CG. Therefore, both groups could be considered equivalent. All reliability scores $\left(\mathrm{ICC}_{1,1}\right)$ of the variables assessed at pre and post-test were above 0.600 , which indicated that all tests could be considered substantially reliable (Beckerman et al., 2001).

Regarding inter-group comparison, it was not significant in any dependent variable at pretest. However, the results of the MANCOVA conducted to assess the pre-test, post-test change on several dependent variables revealed a significant post-test difference between the experimental and the control group: Wilks' Lambda $=.478, F_{(4,25)}=6.837, p=.001, \eta=0.522$. Complementary descriptive analyses and ANCOVAs were conducted to assess the pre-test, post-test difference on each variable between groups. They showed statistically significant differences, favouring the EG (Table 3) in acceleration and agility (Figure 1), and the SJ and CMJ (Figure 2).
A series of MANCOVAs were conducted to assess the pre-test, post-test change on the remaining dependent variables: Bipedal Firm surface $\left(\right.$ Wilks' Lambda $=0.623, F_{(9,15)}=1.009, p=$ $0.474, \eta=0.377$ ), Right Leg Firm surface (Wilks' Lambda $=0.584, F(9,15)=1.185, p=0.371, \eta=0.416)$, and Left Leg Firm surface (Wilks' Lambda $=0.253$, $\left.F_{(9,15)}=4.928, p=0.003, \eta=.747\right)$. They revealed significant post-test differences between the EG and the CG. Complementary descriptive analyses and ANCOVAs were conducted to assess the pretest, post-test difference on each variable between groups. They showed statistically significant differences, favouring the EG, in several of them (Table 3): in the bipedal support on a firm surface: Area, and for the left leg on a firm surface: Length, Area (Figure 3) and Speed.

EG participants reported an average RPE of $12.82 \pm 1.39$ on the training program. LRPE data revealed that quadriceps $(26.7 \%)$, gastrocnemius $(14.81 \%)$ and tibialis anterior $(12.57 \%)$ received the highest ratings. Soleus $(8.88 \%)$, foot muscles (6.97\%), gluteus (6.64\%), hamstrings (6.42\%), rectus abdominis $(4.16 \%)$, and peroneus longus (3.81\%) were also mentioned.

\begin{tabular}{|c|c|c|}
\hline \multicolumn{3}{|c|}{ Participants' demographics and baseline characteristics. } \\
\hline Demographics & $\mathrm{CG}(\mathrm{N}=16)$ & $\mathrm{EG}(\mathrm{N}=18)$ \\
\hline Age (years) & $16.12 \pm 0.50$ & $17.11 \pm 0.75$ \\
\hline Body height $(\mathrm{cm})$ & $175.63 \pm 5.57$ & $176.17 \pm 7.25$ \\
\hline Body mass (kg) & $69.56 \pm 6.11$ & $66.73 \pm 6.63$ \\
\hline Body fat (mm) & $49.89 \pm 12.97$ & $47.08 \pm 9.39$ \\
\hline \multicolumn{3}{|c|}{ Note: Data expressed as mean $\pm S D$. } \\
\hline
\end{tabular}


Table 2

Complete slackline training program conducted in the project.

\begin{tabular}{|c|c|c|c|}
\hline Week & Tasks & Repetitions & $\begin{array}{c}\text { Time } \\
\text { (work/rest) }\end{array}$ \\
\hline 1 & $\begin{array}{l}\text { Tandem stance } \\
\text { Single stance - left leg } \\
\text { Single stance - right leg }\end{array}$ & 3 & $30 / 10$ \\
\hline 2 & $\begin{array}{l}\text { Tandem stance } \\
\text { Single stance - left leg } \\
\text { Single stance - right leg }\end{array}$ & 3 & $30 / 10$ \\
\hline 3 & $\begin{array}{l}\text { Tandem stance } \\
\text { Single stance - left leg } \\
\text { Single stance - right leg } \\
\text { Lateral stance (surf) }\end{array}$ & 3 & $30 / 10$ \\
\hline 4 & $\begin{array}{l}\text { Tandem stance } \\
\text { Single stance - left leg } \\
\text { Single stance - right leg } \\
\text { Lateral stance (surf) }\end{array}$ & 3 & $30 / 10$ \\
\hline 5 & $\begin{array}{l}\text { Single stance - left leg } \\
\text { Single stance - right leg } \\
\text { Lateral stance (surf) } \\
\text { Forward-backward steps }\end{array}$ & 3 & $30 / 10$ \\
\hline 6 & $\begin{array}{l}\text { Single stance - left leg } \\
\text { Single stance - right leg } \\
\text { Lateral stance (surf) } \\
\text { Forward-backward steps }\end{array}$ & 3 & $30 / 10$ \\
\hline
\end{tabular}

Note: Time in seconds.

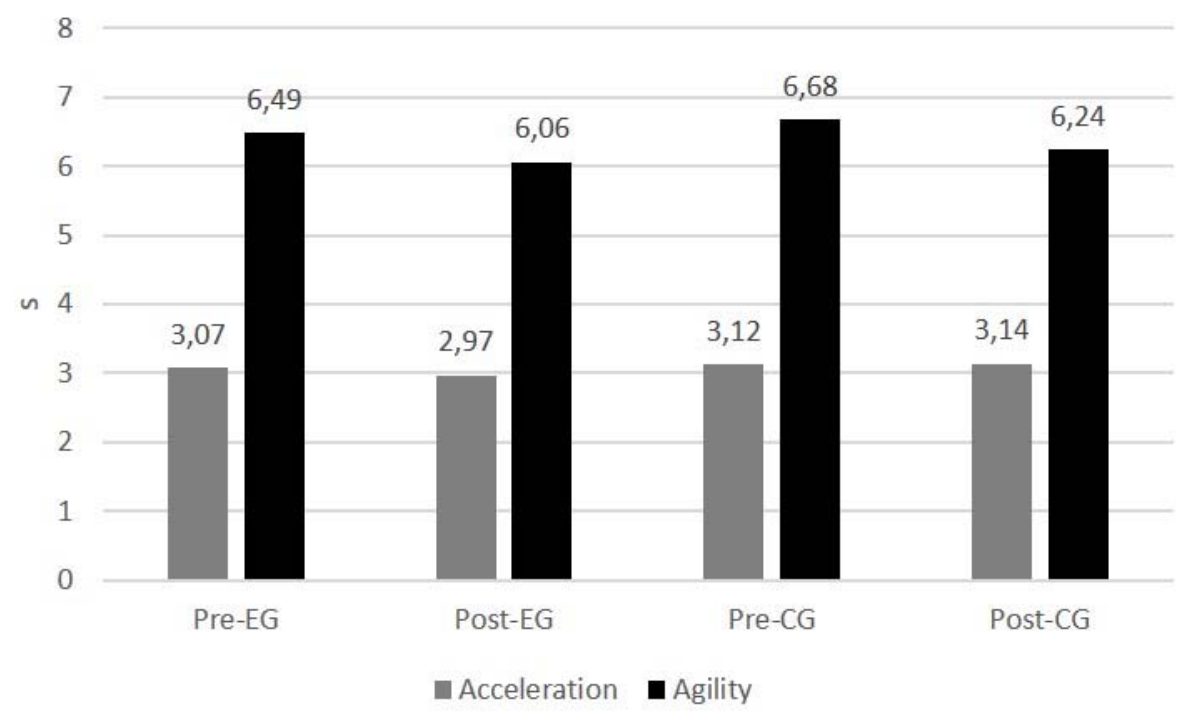

Figure 1

Acceleration and agility pre-test, post-test differences among groups.

Note: Pre: Pre-test; Post-Post-test; EG: Experimental group; CG: Control group. 


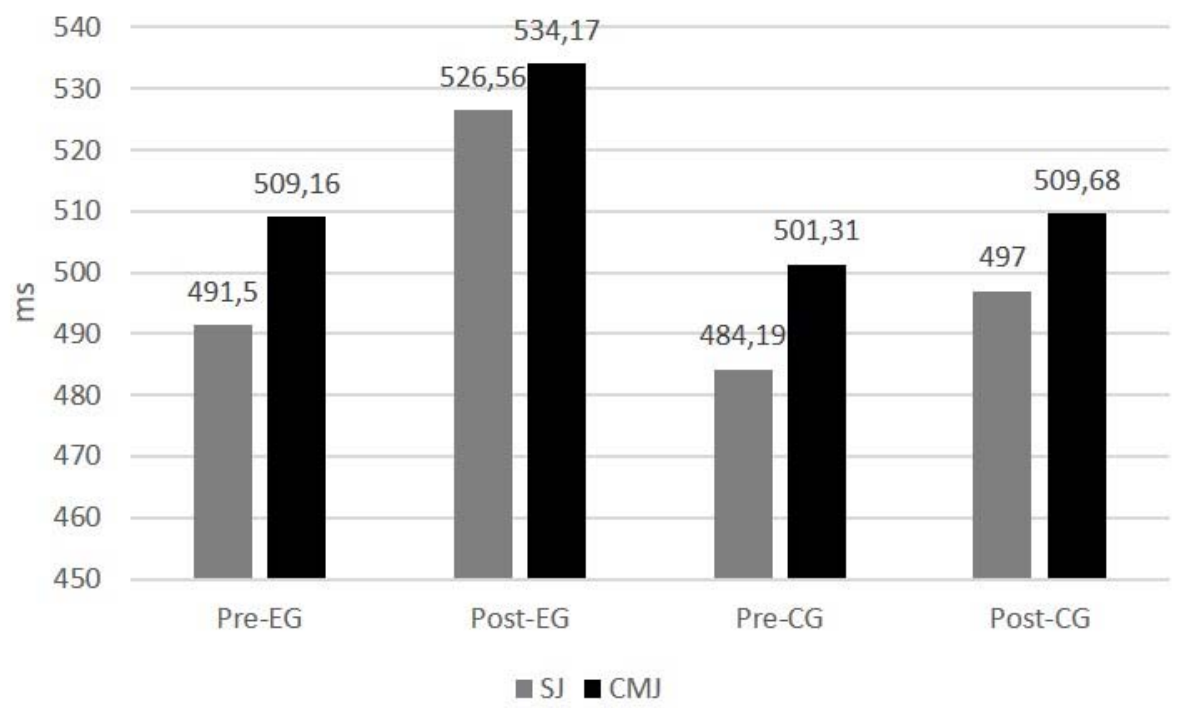

Figure 2

SJ and CMJ pre-test, post-test differences among groups.

Note: Note: SJ: Squat jump; CMJ: Countermovement jump; Pre: Pre-test; Post-Post-test; EG: Experimental group; CG: Control group.

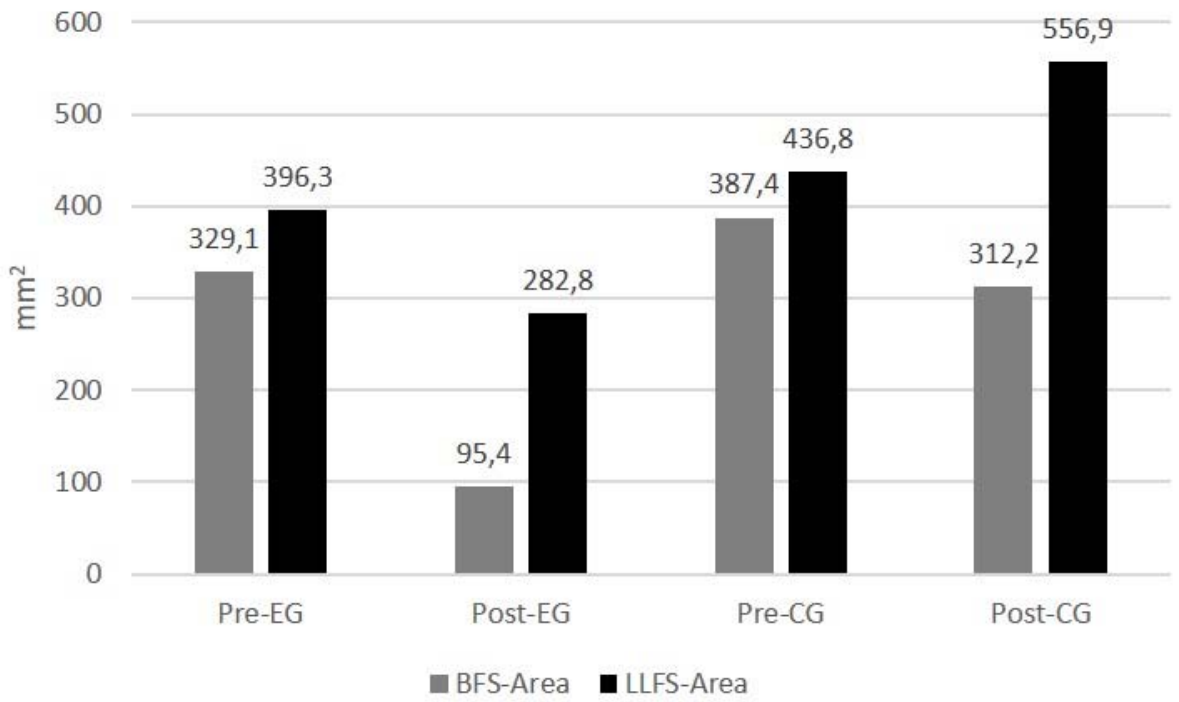

Figure 3

CoP Area pre-test, post-test differences among groups.

Note: BFS: Bipedal firm surface; LLFS: Left leg firm surface; Pre: Pre-test; Post-Post-test; EG: Experimental group; CG: Control group. 
Table 3

Acceleration, agility, force production and $\mathrm{CoP}$ measurements in the experimental and control groups at pre and post training.

\begin{tabular}{|c|c|c|c|c|c|c|}
\hline & & \multicolumn{2}{|c|}{ Experimental Group } & \multicolumn{2}{|c|}{ Control Group } & \multirow[t]{2}{*}{ ES } \\
\hline & & $\begin{array}{l}\text { Pre- } \\
\text { test }\end{array}$ & $\begin{array}{c}\text { Post- } \\
\text { test }\end{array}$ & $\begin{array}{l}\text { Pre- } \\
\text { test }\end{array}$ & $\begin{array}{l}\text { Post- } \\
\text { Test }\end{array}$ & \\
\hline Acceleration & $\mathrm{s}$ & $3.07 \pm 0.13$ & $2.97 \pm 0.12^{*}$ & $3.12 \pm 0.12$ & $3.14 \pm 0.11$ & 0.405 \\
\hline Agility & $\mathrm{s}$ & $6.49 \pm 0.72$ & $6.06 \pm 0.12^{* *}$ & $6.68 \pm 0.17$ & $6.24 \pm 0.19$ & 0.212 \\
\hline Squat Jump & $\mathrm{ms}$ & $491.5 \pm 35.82$ & $526.56 \pm 35.88^{*}$ & $484.19 \pm 39.66$ & $497.00 \pm 26.09$ & 0.245 \\
\hline $\begin{array}{l}\text { Counter } \\
\text { Movement } \\
\text { Jump }\end{array}$ & $\mathrm{ms}$ & $509.16 \pm 28.53$ & $534.17 \pm 32.91^{* *}$ & $501.31 \pm 44.52$ & $509.68 \pm 21.74$ & 0.252 \\
\hline $\begin{array}{c}\text { Bipedal Firm } \\
\text { Surface }\end{array}$ & $\begin{array}{l}\text { Area } \\
\mathrm{mm}^{2}\end{array}$ & $329.10 \pm 256.64$ & $95.4 \pm 151.19^{* *}$ & $387.45 \pm 202.40$ & $312.2 \pm 150.21$ & 0.303 \\
\hline \multirow[t]{3}{*}{$\begin{array}{c}\text { Left Leg Firm } \\
\text { Surface }\end{array}$} & $\begin{array}{l}\text { Lengt } \\
\mathrm{h} \mathrm{mm}\end{array}$ & $178.82 \pm 51.11$ & $134.13 \pm 38.41^{* *}$ & $173.75 \pm 51.44$ & $180.47 \pm 44.86$ & 0.160 \\
\hline & $\begin{array}{l}\text { Area } \\
\mathrm{mm}^{2}\end{array}$ & $396.39 \pm 178.31$ & $282.86 \pm 120.98^{*}$ & $436.87 \pm 213.32$ & $556.99 \pm 166.97$ & 0.471 \\
\hline & $\begin{array}{l}\text { Speed } \\
\mathrm{mm} / \mathrm{s}\end{array}$ & $16.38 \pm 4.20$ & $13.61 \pm 3.56^{* *}$ & $15.55 \pm 4.91$ & $17.95 \pm 6.31$ & 0.177 \\
\hline \multicolumn{7}{|c|}{ Note: Data expressed as mean \pm standard deviation. ${ }^{* *} p<0.05 ;{ }^{*} p<0.01$} \\
\hline
\end{tabular}

\section{Discussion}

The goal of the present study was to assess the effects of a supervised slackline training program in a group of youth soccer players. Results showed significant improvements in the participants' acceleration, agility, jump performance and postural control at post-tests. The program was rated as "somewhat hard" by the players, and the quadriceps, the gastrocnemius and the tibialis anterior were mentioned as the most exerted muscles while slacklining.

Regarding the first hypothesis, results showed that the program produced positive effects on the soccer players' 20-m acceleration, agility and jumping performance. To our knowledge, this is the first published study on the effects of 
slacklining on athletes' acceleration and agility, and it indicates that this type of cross-training exercise could be of great help to develop both variables in soccer players. This finding could be considered remarkable because soccer players perform between 1000-1400 short activities during a game (Mohr et al., 2003; Stølen et al., 2005). Gamble (2012) included strength qualities as trainable determinants of acceleration, but also postural control and stability. It has been hypothesized that when individuals try not to fall from the polyester band, balance demand increases, challenging the participants' postural control and stability systems and, possibly, influencing their acceleration. On the other hand, agility has been defined as the ability to maintain and control a correct body position while quickly changing direction (Sporis et al., 2010). Research has showed that it requires the combination of several physical / physiological abilities such as speed, balance, power and coordination (Goral, 2015). Results from the present study indicate that some of these abilities could have been stimulated by the slackline training program. This finding can be considered noteworthy because soccer players have been found to change direction every 2-4 s (Verheijen, 1997). Therefore, agility could be considered a key element for soccer players, since its improvement has been connected with a positive impact on their performance (Little and Williams, 2005). Results from the present study indicate that a slackline training program can help improve soccer players' acceleration and agility.

Regarding the participants' jumping performance, results showed that high-level youth soccer players significantly improved their SJ and $\mathrm{CMJ}$ scores after a supervised slackline training program. This is notable, because strength and power have been considered as important as endurance for high-level soccer play (Stølen et al., 2005). Two mechanisms have been described as fundamental in strength development: muscular hypertrophy and neural adaptations (Stølen et al., 2005). The slackline training's workload has been considered "somewhat hard" by our players and other athletes in previous studies (Santos et al., 2014, 2016). Therefore, neural adaptations and not muscular hypertrophy could be considered the major responsible for the gains obtained in this group of soccer players' jump performance, but also in judoists (Santos et al., 2014) and in female basketball players (Santos et al., 2016). Neural adaptations include selective activation of motor units and muscles, and increased firing frequency of nerve impulses (Stølen et al., 2005). When individuals try not to fall from the slackline band, motor units are highly recruited to avoid falls. This could have produced neural adaptations, increasing the players' SJ and CMJ performance. Of course, this is speculative at this time. Previous studies have reported contradictory results in athletes' jumping performance after slacklining: positive gains in CMJ scores in judokas and basketball players (Santos et al., 2014, 2016), but not in the drop-jump test or the 30-s maximal performance jump test, respectively. In the present study, slackline training did have a positive impact on soccer players jumping performance assessed through the SJ and CMJ tests.

The second hypothesis was that the program would have a positive effect on the participants' postural control. Results showed that several CoP variables significantly improved only in the players that experienced the slackline training program: area in the bipedal support on a firm surface, and length, area and speed in the left leg support on a firm surface. Previous studies also reported significant improvements in several postural control variables in athletes: judokas (Santos et al., 2014) and female basketball players (Santos et al, 2016), as well as children (Donath et al., 2013), and young healthy adults (Granacher et al., 2010; Keller et al., 2012; Pfusterchmied et al., 2013a). The only study conducted in youth soccer players showed larger training effects of slackline training compared to the FIFA 11+ programme (Jäger et al., 2017), and our results reinforce this idea. Slacklining produces very high movement variability and very fast mediolateral disturbances to the body (Pfusterchmied et al., 2013a). These seem to stimulate the individual's PCS in the medio-lateral and the anterior-posterior directions (Santos et al., 2016). Our results showed that the slackline training program improved soccer players' positioning variables (length, area and speed), and these improvements were more evident in the players' left leg (non-dominant) and when they were placed over an unstable platform. These results are in line with previous studies conducted on basketball players (Santos et al., 2016). The non-dominant leg tends to be weaker and less skilled, demanding lower intensity stimuli 
to improve and the large number of single stance slackline training tasks could have also helped. Since slacklining provides a highly movable surface, gains should be more evident on tests conducted on compliant surfaces.

The third and final hypothesis was that the supervised slackline program would be rated as light in the 6-20 Borg' scale, and that the leg muscles would be the most exerted. Results showed that players that followed slackline training rated the program as "somewhat hard". Previous studies conducted with judokas and basketball players produced similar results (Santos et al., 2014, 2016). Three different types of athletes have agreed that slacklining is not a demanding exercise. Therefore, it can be easily introduced in any training schedule. More important, researchers observed that athletes considered it an enjoyable activity, which is important to motivate them in long, tiring training sessions along a regular season. On the other hand, results also showed that quadriceps, gastrocnemius and tibialis anterior were perceived by the players as most exerted muscles during the slackline training program. Previous studies on judokas and basketball players (Santos et al., 2014, 2016) also identified the first two muscles as most involved. In a recent article, Gable et al. (2015) found significantly increased activation and recruitment in the quadriceps muscle in a group of knee-injured individuals after experiencing slackline training. Soleus, hamstrings, tibialis, and peroneus muscles were also mentioned by the soccer players in this study and by the judokas and basketball players in previous studies. Some of these have been identified as major postural leg muscles (Sozzi et al., 2013). Their activation could be responsible for the improvements observed in several CoP variables. Other muscles that were also mentioned (quadriceps, hamstrings, gastrocnemius and soleus) have been linked to jump performance and running speed in soccer (Bangsbo, 1993), and results from the present study support this idea. Slacklining seemed to have activated these leg muscles, increasing the players' $\mathrm{CoP}$ variables, jump performance (SJ, CMJ) and acceleration (20m sprint test).

Performance in soccer has been closely linked to high-speed actions such as sprints, direction changes and jumps (Hoff and Helgerud, 2004). They have been considered the most decisive elements in soccer, because most goals are preceded by one or a combination of several of them (Faude et al., 2012). Therefore, players with augmented capacities could have an advantage over their rivals. Results from the present study showed that supervised slackline training produced significant gains in high-level youth soccer players' acceleration, agility, SJ and CMJ performance, as well as PCS. Therefore, it should be considered a valid instrument to increase young players' performance. Coaches are always looking for new training tools that require less time, are easy to use and can increase athletes' motivation when their compliance is declining, and slacklining seems to fulfil all these pre-requisites.

In conclusion, slackline training produced significant positive effects on high-level, under 19 soccer players' acceleration, jump performance and PCS variables. Although quadriceps, gastrocnemius and tibialis anterior were the most exerted muscles while slacklining, RPE scores indicated that it was not a strenuous exercise. The program included simple tasks during short periods of time that can be easily integrated into the players' daily training routine. Coaches could use similar slackline training protocols to include this tool in their practices and benefit their players.

The present study also holds several limitations. First, the number of participants could be considered limited. Similar studies should be conducted in larger cohorts of soccer players. Second, the present study was implemented in young male players. Further studies should be conducted in older players, and female athletes. Finally, changes in the players' PCS were assessed through CoP measurements. An analysis of the centre of mass could provide a deeper view. 


\section{References}

Bangsbo J. The physiology of soccer - with special reference to intense intermittent exercise. Acta Physiol Scand, 1993; 151: 143-156

Beckerman H, Roebroeck ME, Lankhorst GJ, Becher JG, Bezemer PD, Verbeek AL. Smallest real difference, a link between reproducibility and responsiveness. Qual Life Res, 2001; 10: 571-578

Bieć E, Giemza C, Kuczyński M. Changes in postural control between 13-and 19-year-old soccer players: is there a need for a specific therapy? J Phys Therapy Science, 2015; 27(8): 25-55

Borg G. Borg's serceived exertion and pain scales. Leeds: Human Kinetics; 1998

Bosco C, Luhtanen P, Komi PV. A simple method for measurement of mechanical power in jumping. Eur J Appl Physiol, 1983; 50: 273-282

Donath L, Roth R, Rueegge A, Groppa M, Zahner L, Faude O. Effects of slackline training on balance, jump performance muscle activity in young children. Int J Sports Med, 2013; 34(12): 1093-1198

Donath L, Roth R, Zahner L, Faude O. Slackline training and neuromuscular performance in seniors: A randomized controlled trial. Scand J Med Sci Sport, 2016; 26(3): 275-283

Faude O, Koch T, Meyer T. Straight sprinting is the most frequent action in goal situations in professional football. J Sports Sci, 2012; 30: 625-631

Gabel CP, Osborne J, Burkett B. The influence of Slacklining on quadriceps rehabilitation, activation and intensity. J Sci Med Sport, 2015; 18(1): 62-66

Gamble P. Training for Sports Speed and Agility: An Evidence-based Approach. Oxon: Routledge; 2012

Goral K. Examination of agility performances of soccer players according to their playing positions. The Sport Journal; 2015. Available at: http://thesportjournal.org/article/examination-of-agility-performances-ofsoccer-players-according-to-their-playing-positions/; accessed on 15.06.2017

Granacher U, Iten N, Roth R, Gollhofer A. Slackline training for balance and strength promotion. Int J Sports Med, 2010; 31: 717-723

Hoff J, Helgerud J. Endurance and strength training for soccer players: physiological considerations. Sports Med, 2004; 34: 165-180

Jäger T, Kiefer J, Werner, I, Federov PA. Could slackline training complement the FIFA 11+ programme regarding training of neuromuscular control? Eur J Sport Sci, 2017; 17(8): 1021-1028

Keller M, Pfusterschmied J, Buchecker M, Müller E, Taube W. Improved postural control after slackline training is accompanied by reduced H-reflexes. Scand J Med Sci Sport, 2012; 22(4): 471-477

Little T, Williams AG. Specificity of acceleration, maximum speed, and agility in professional soccer players. J Strength Cond Res, 2005; 19: 76-78

Martin WE, Bridgmon KD. Quantitative and statistical research methods: from hypothesis to results. San Francisco: John Wiley Sons; 2012

McGuine TA, Greene JJ, Best T, Leverson G. Balance as a predictor of ankle injuries in high school basketball players. Clin J Sport Med, 2000; 10(4): 239-244

Mohr M, Krustrup P, Bangsbo J. Match performance of high- standard soccer players with special reference to development of fatigue. J Sports Sci, 2003; 21(7): 519-528

Morgan WP, Borg GAV. Perception of effort in the prescription of physical activity. Chicago: American Medical Association, 126-129; 1976 
Mouzat A, Dabonneville M, Bertrand P. The effect of feet position on orthostatic posture in a female sample group. Neurosci Let, 2004; 365(2): 79-82

Nilsson J, Csergö S, Gullstrand L, Tveit P, Refsnes PE. Work-time profile, blood lactate concentration and rating of perceived exertion in the 1998 Greco-Roman wrestling World Championship. J Sport Sci, 2002; 20(11): 939-945

Paillard T, Noe F. Effect of expertise and visual contribution on postural control in soccer. Scand J Med Sci Sport, 2006; 16: 345-348

Pfusterschmied J, Buchecker M, Keller M, Wagner H, Taube W, Müller E. Supervised slackline training improves postural stability. Eur J Sport Sci, 2013a; 13(1): 49-57

Pfusterschmied J, Stöggl T, Buchecker M, Lindinger S, Wagner H, Müller E. Effects of 4-week slackline training on lower limb joint motion and muscle activation. J Sci Med Sport, 2013b; 16(6): 562-566

Ruhe A, Fejer R, Walker B. The test-retest reliability of centre of pressure measures in bipedal static task conditions - A systematic review of the literature. Gait Posture, 2010; 32: 436-445

Santos L, Fernández-Río J, Fernández-García B, Jakobsen MD. The effects of supervised Slackline Training on postural balance in judoists. Med Sport, 2014; 67(4): 539-553

Santos L, Fernández-Río J, Fernández-García B, Jakobsen MD, González GL, Suman OE. Effects of slackline training on postural control, jump performance and myoelectrical activity in female basketball players. J Strength Cond Res, 2016; 30(3): 653-664

Sozzi E, Honeine JL, Do MC, Schieppati M. Leg muscle activity during tandem stance and the control of body balance in the frontal plane. Clin Neurophysiol, 2013; 124: 1175-1186

Sporis G, Jukic I, Milanovic L, Vucetic V. Reliability and factorial validity of agility tests for soccer players. J Strength Cond Res, 2010; 24(3): 679-686

Stølen T, Chamari K, Castagna C, Wisløff U. Physiology of soccer. Sports Med, 2005; 35(6): 501-536

Thomas M, Kalicinski M. The Effects of Slackline Balance Training on Postural Control in Older Adults. J Aging and Physical Activity, 2016; 24(3): 393-398

Turner AN, Stewart PF. Strength and conditioning for soccer players. Strength Cond J, 2014; 36(4): 1-13

Verheijen R. Handbuch fur Fussballkondition. Leer: BPFVersand; 1997

Weir JP. Quantifying test-retest reliability using the intraclass correlation coefficient and the SEM. J Strength Cond Res, 2005; 19: 231-240

Wisløff U, Castagna C, Helgerud J, Hoff J. Maximal squat strength is strongly correlated to sprint performance in elite soccer players. Brit J Sports Med, 2004; 38(3): 285-288

\section{Corresponding author:}

\section{Javier Fernandez-Rio}

Universidad de Oviedo

c) Aniceto Sela, s/n, despacho 219

33005-Oviedo-Asturias, Spain

Tel: +0034-985102850

Fax: +0034-985103226

E-mail: javier.rio@uniovi.es 